\title{
Neuroprosthetic Rehabilitation of Acquired Skull Defects
}

\author{
Ankit Sharma \\ MDS Student, Department of Prosthodontics, Government Dental College, Kottayam, Kerala, India
}

Correspondence: Ankit Sharma, MDS Student, Department of Prosthodontics, Government Dental College, Kottayam, Kerala India, e-mail: ankitcmc@gmail.com

\section{ABSTRACT}

Cranial defects can be broadly classified as congenital and acquired defects. Among the congenital defects, encephalocele is the most common cause while trauma, infections and tumors form the bulk of the acquired skull defects. There has been large number of cranial injuries occurring in this modern age requiring the skull reconstruction not only for rehabilitating the skull cosmesis but also improving the neurological status of the patient. The reconstruction of the cranial defects using alloplastic materials opens a new field for the prosthodontist, in which he can render a worth-while health service to the society. This article illustrates a case report of neuroprosthetic rehabilitation of a patient who had a road traffic accident sustaining multiple bone fractures, including skull followed by decompressive craniectomy and cranioplasty using a Titanium cranial prosthesis with prosthodontists and neurosurgeons working as a team, thereby improving his neurological status and cosmesis. Keywords: Cranioplasty, Neuroprosthetic rehabilitation, Acquired skull defects, Titanium cranial prosthesis.

\section{INTRODUCTION}

Cranial defects occur among all ages from a wide variety of causes, such as trauma, infection, congenital malformations, pathology and tumors, and their surgical management can all lead to skull abnormalities and defects. Small defects that are covered in formidable soft tissue may not need repair. Other cranial defects require secondary reconstruction. Cranioplasty is defined as the repair of a cranial defect or deformity. Repair of cranial defects is indicated to protect underlying brain tissue, provide pain relief at the defect site, improve cosmesis and minimize patient anxiety. ${ }^{1-3}$ Cranioplasty is accomplished either with osteoplastic reconstruction or restoration with alloplastic materials that include metal, acrylic resin, polyethylene and silicone.

\section{CASE REPORT}

A 24-year-old male patient had a history of road traffic accident and sustained multiple bone fractures, including the skull. The patient underwent decompressive craniectomy in the Department of Neurosurgery, Government Medical College, Kottayam, and was referred to the Department of Prosthodontics, Government Dental College, Kottayam, for fabrication of cranial prosthesis for the purpose of cranioplasty. The defect involved the parts of left frontal, parietal and temporal bone. The size of the defect was $16 \mathrm{~cm} \times 9 \mathrm{~cm} \times 6 \mathrm{~cm}$ (Fig. 1).

\section{Impression Procedure}

The cleanly shaved skull defect of the patient was gently palpated to identify the periphery of the cranial defect. An indelible pen line was marked about $3 \mathrm{~mm}$ beyond to indicate the outermost border of the prosthetic device to be fabricated (Fig. 2). The wax was adapted to the defect margin to serve as

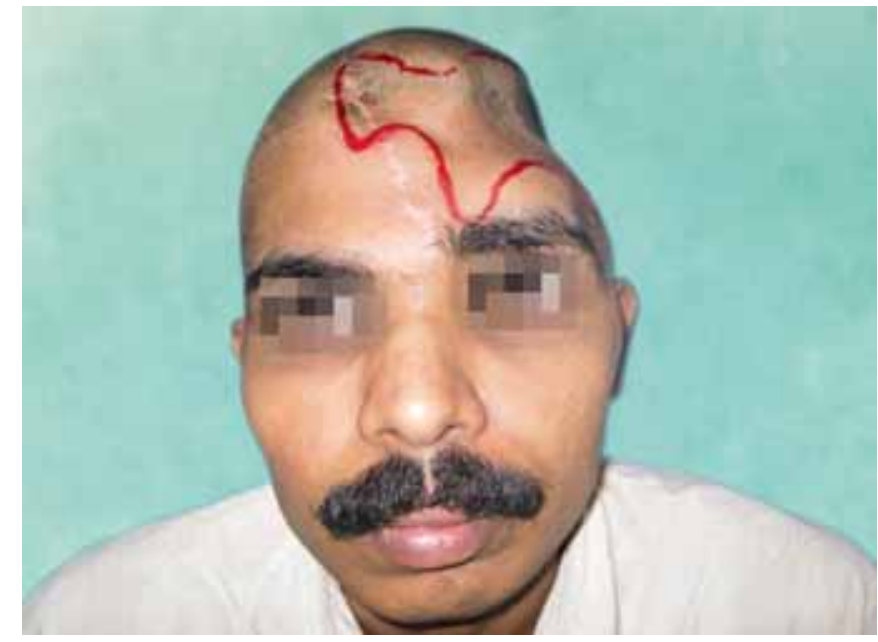

Fig. 1: Preoperative view of the patient showing the skull defect

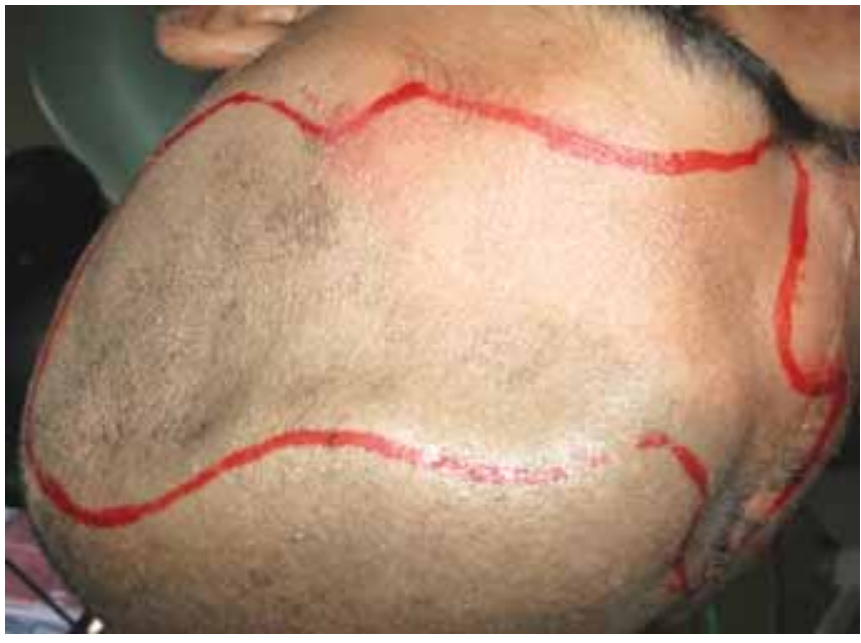

Fig. 2: Extent of the skull defect 
a retaining dam for the impression material. A smooth, lightly mixed alginate hydrocolloid impression material was then poured onto the defect area starting at the highest point and allowing the mixture to flow downward to avoid trapping air. Tufts of cotton were placed over the alginate just at the time it was about to set, in order to act as a binding unit between the alginate and lightly mixed Plaster of Paris, which was poured over it (Figs 3A and B). The Plaster of Paris provided a rigid support to the impression material and also prevented dimensional distortion during the removal of set alginate material from the patient's head. Dental stone plaster was mixed and poured onto the alginate impression to obtain positive likeness of the patient's skull (Fig. 4). The markings on the stone cast are not as concise as originally placed. Therefore, the center of the line was assumed to be the original border. ${ }^{4}$ Prior to fabrication of the cranial prosthesis, the neurosurgeon should be consulted and the design of the cranial prosthesis discussed.

\section{Trial of the Wax Prosthesis}

A wax pattern was then made to the exact dimension and contour of the skull defect image derived from the positive
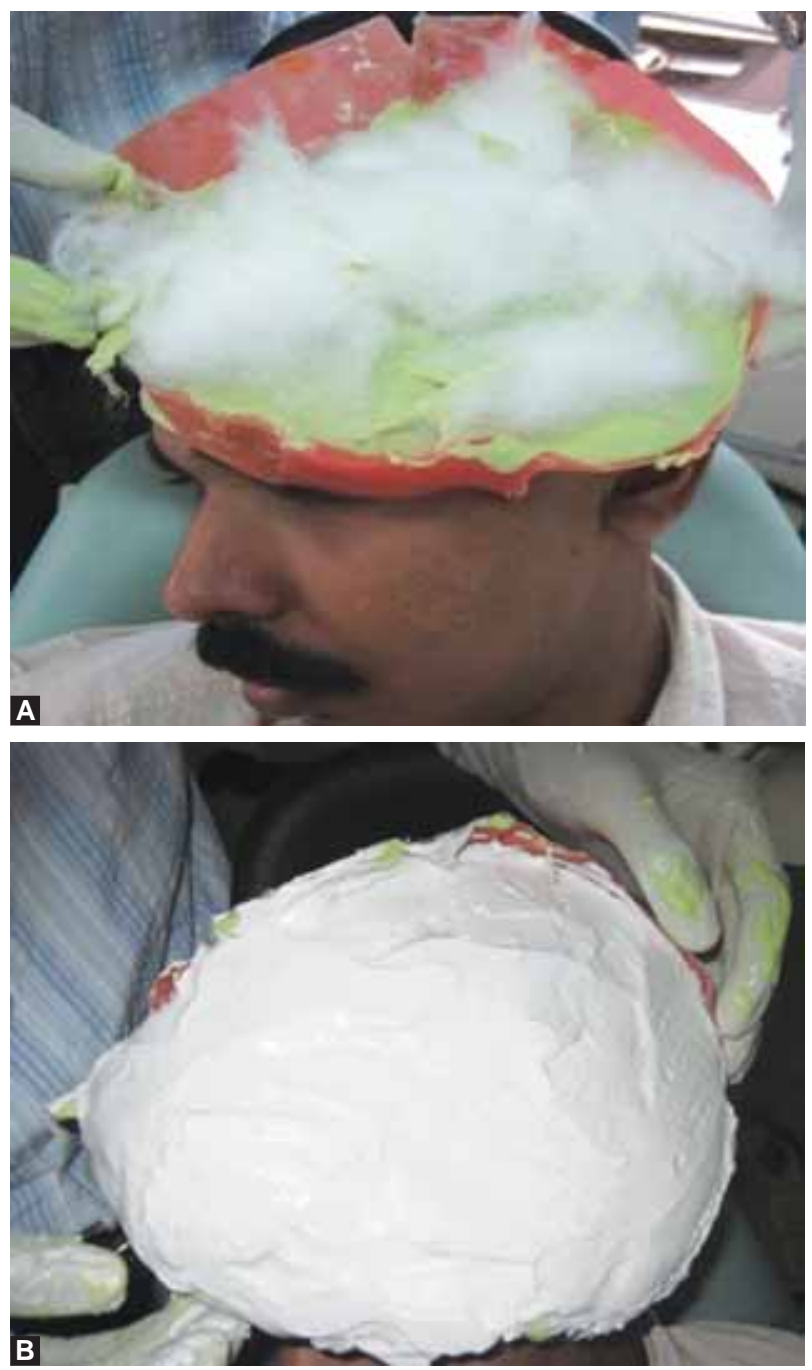

Figs $3 A$ and B: Impression making of the defect

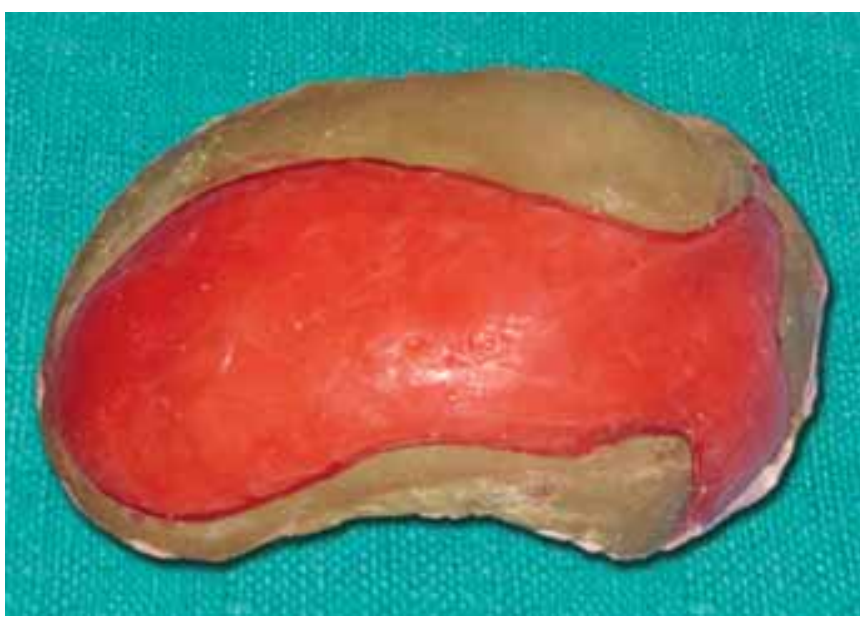

Fig. 4: Wax build-up of the defect

replica of the stone cast. At this stage, the patient was recalled for a try-in, in order to ensure a proper fit of the wax skulldefect pattern. During the try-in stage, the necessary corrections were made to make the wax pattern matched to the contour of the normal contralateral side of the skull. The margins of the wax prosthesis were also inspected to be merged with margins of the defect (Figs 5A and B).

\section{Titanium Plate Fabrication}

A titanium plate was fabricated out of the medical grade titanium sheet using this wax pattern as a mould (Jayon Implant Pvt Ltd. Lab, Kanjikode, Palakkad, Kerala) and $2 \mathrm{~mm}$ holes were drilled throughout the plate (Fig. 6). These perforations prevent development of an epidural hematoma, permit escape of underlying fluid and its absorption by the lymphatics of the scalp, and allow for ingrowth of fibrous connective tissue to assist in stabilization. The holes also provide a means of securing the cranial prosthesis to the bony defect. ${ }^{1}$ A number of surgeons have commented on the frequency of complications in unperforated plates. In a few instances, solid plates giving rise to trouble have been successfully replaced immediately after multiple drill holes were made. ${ }^{5}$

To prevent the sharp margins of the holes from cutting the sutures, later used in its insertion, it is necessary that the holes be countersunk on both the inner and outer surface. The titanium plate was then autoclaved and made ready to be surgically placed under the scalp.

\section{Surgical Placement of the Prosthesis}

The patient was brought to the operating room and placed in a supine position for oral endotracheal intubation. The planned incision is ideally marked over healthy tissue away from the area of reconstruction and should take into account the need for wide exposure, management of the soft tissue, a hidden position of the final scar and tension-free closure. ${ }^{6}$ The cutaneous incision was opened in segments and dissection was then performed bluntly in subgaleal plane, leaving the 

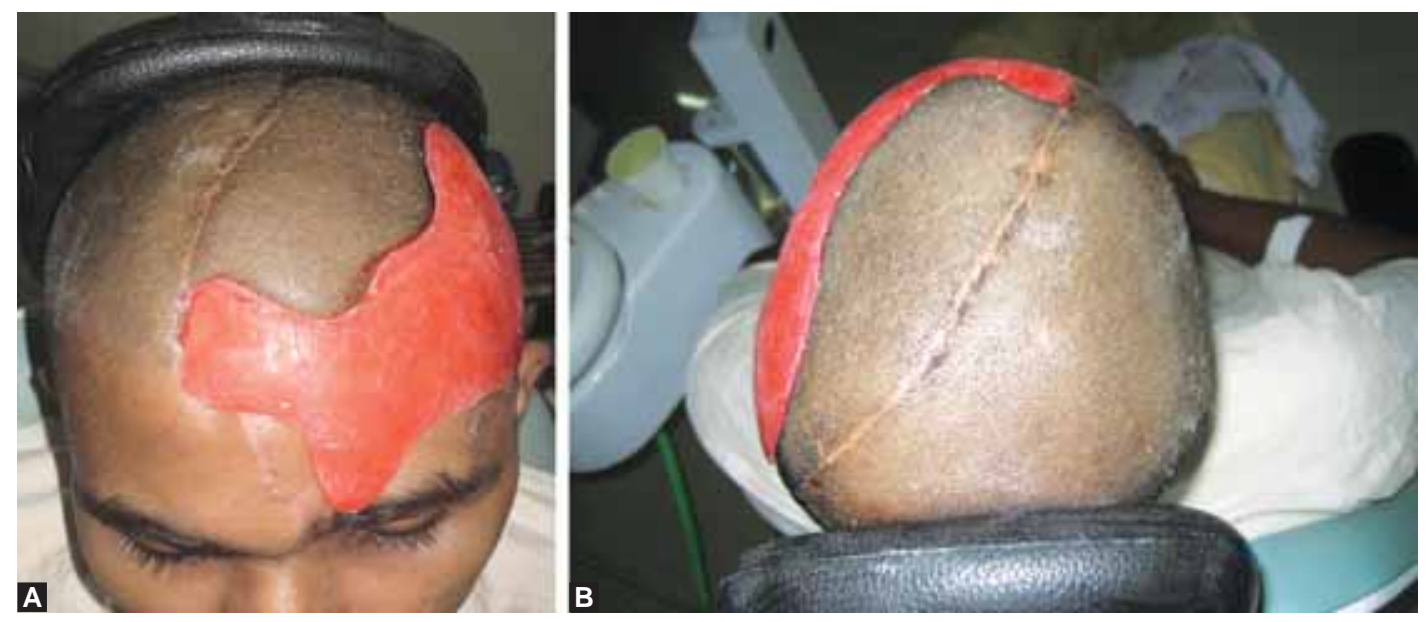

Figs $5 \mathrm{~A}$ and $\mathrm{B}$ : Try-in of the wax cranial prosthesis

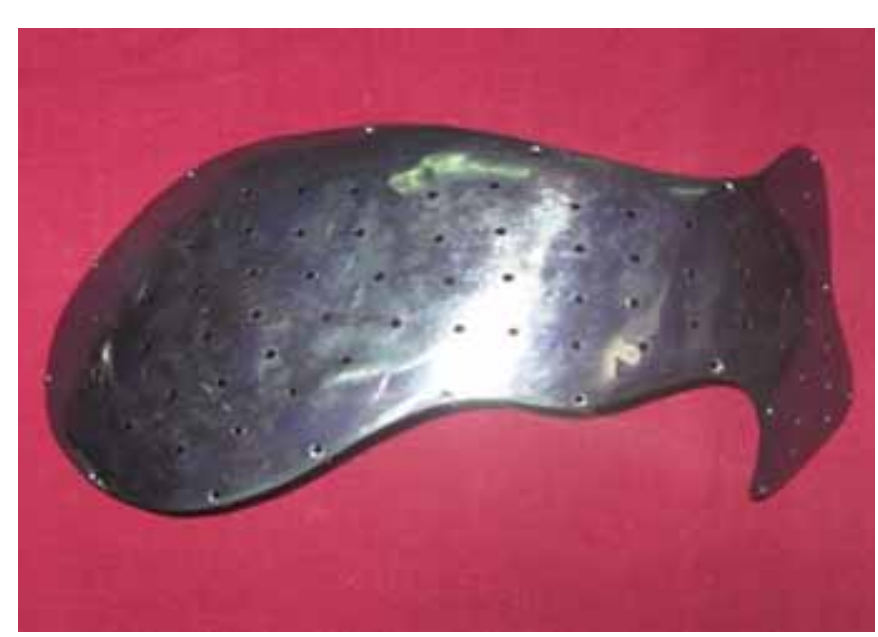

Fig. 6: Titanium cranial prosthesis

pericranium in place. The incision was then retracted with opposing skin hooks and a needle tip cautery device used to cut and coagulate the deeper tissues. Dissection was then continued until the margins of entire defect were delineated in a supraperiosteal plane. The fit of the margins of the cranial prosthesis were checked and found to be accurate (Fig. 7). Corresponding to the periphery holes on the plates, certain markings were made over the intact bony margin using electrocautery. With no. 40 bone bur, holes were drilled through the outer table of skull into the diploe layer of the bone at the points previously marked under copious saline irrigation. An additional hole was then drilled into the diploe layer so as to contact each of the former holes at right angles (Fig. 8). Then 1-0 proline suture was passed through all these two holes and their corresponding holes on the periphery of the titanium plate giving tripod stability to the plate (Fig. 9). After the initial stabilization with the help of sling sutures the plate was evaluated for bulk, contour, margin thickness, and position, and then finally sutured firmly to the desired area (Fig. 10). Copious antibiotic laden irrigation was done to ensure the wound was free of debris. Closure was then performed in layers using Vicryl to close the underlying galea and subcutaneous

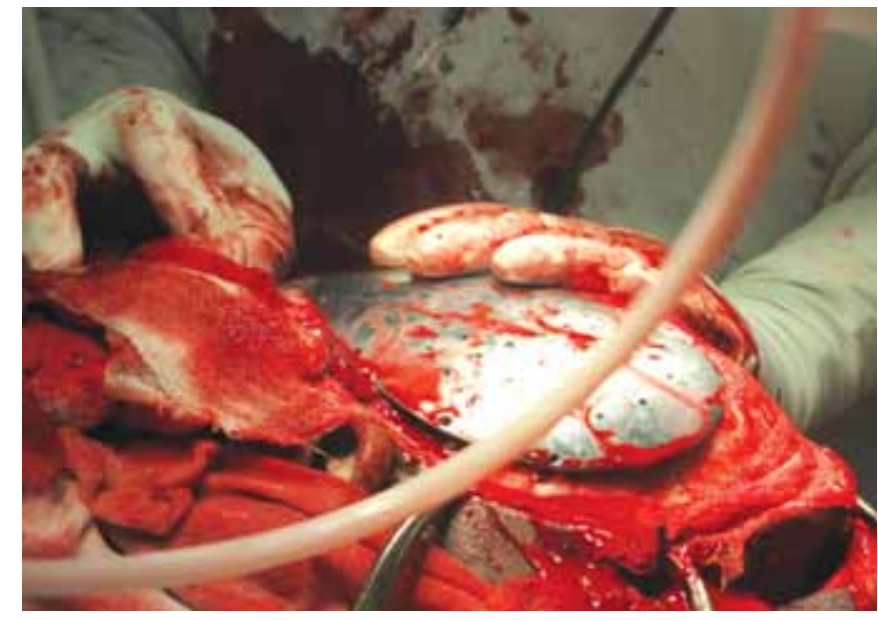

Fig. 7: Assuring the fit of the prosthesis before stabilization

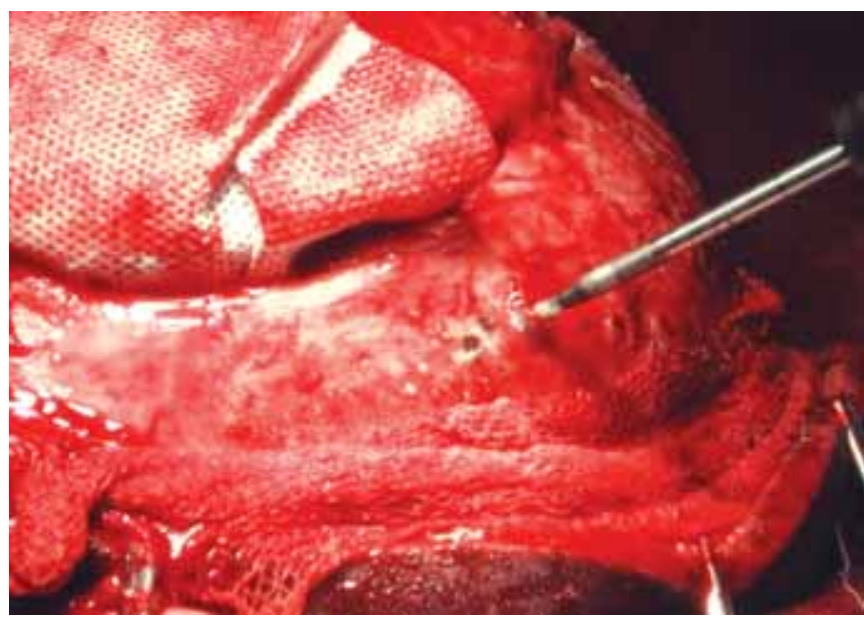

Fig. 8: Drilling of holes into the outer table of skull for stabilization of prosthesis

tissue. The skin was sutured by staple sutures with a drain placed left in place along with compressive turban dressing. The patient was examined in the department of prosthodontics after one week of surgery and there was remarkable improvement in the contour of the skull. The patient was extremely satisfied with 


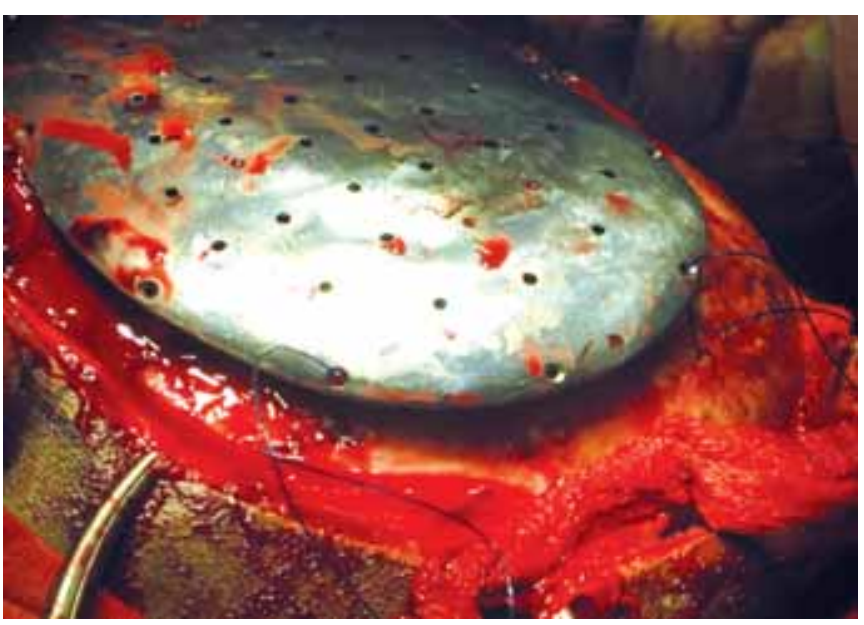

Fig. 9: Initial stabilization of the prosthesis by sling sutures

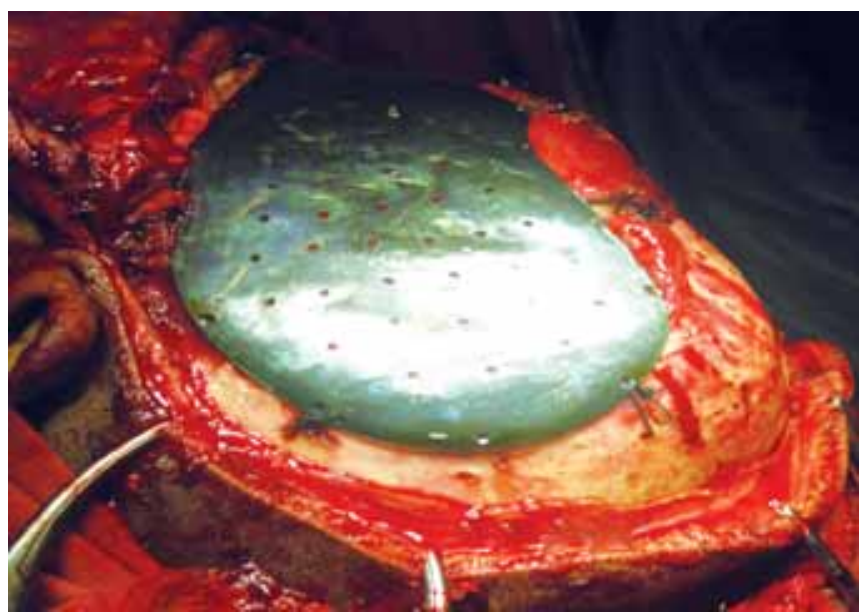

Fig. 10: Cranial prosthesis finally sutured to the defect area

the relief from severe headache and the excellent cosmesis obtained. The patient was reviewed after 4 months and the patient has been leading a normal social life (Figs 11A to C).

\section{DISCUSSION}

Cranioplasty, the surgical repair of the skull defect, is one of the oldest known neurosurgical procedures, dating from the year 3000 BC, when the Paracas Indians in Peru performed procedures to correct large cranial defects. ${ }^{7}$ Cranial decompression has gained popularity in treating elevated intracranial pressure in traumatic brain injury. A full-thickness bone flap is removed and commonly stored in a freezer or subcutaneous abdominal pocket. The most common indication for cranioplasty is the infectious loss of a bone flap after elective craniotomy. ${ }^{8}$ Injuries that are compound and involve infection are best delayed for 6 months to 1 year to allow the surgical bed to heal and be free from infection. Cranioplasties taking place 1 to 6 months after craniectomy had the highest complication rate (7.9\%) and those performed 12 to 18 months after craniectomy had the lowest complication rate (4.5\%). ${ }^{9}$ In the case reported, the cranioplasty was done 7 months after craniectomy to prevent any complication.
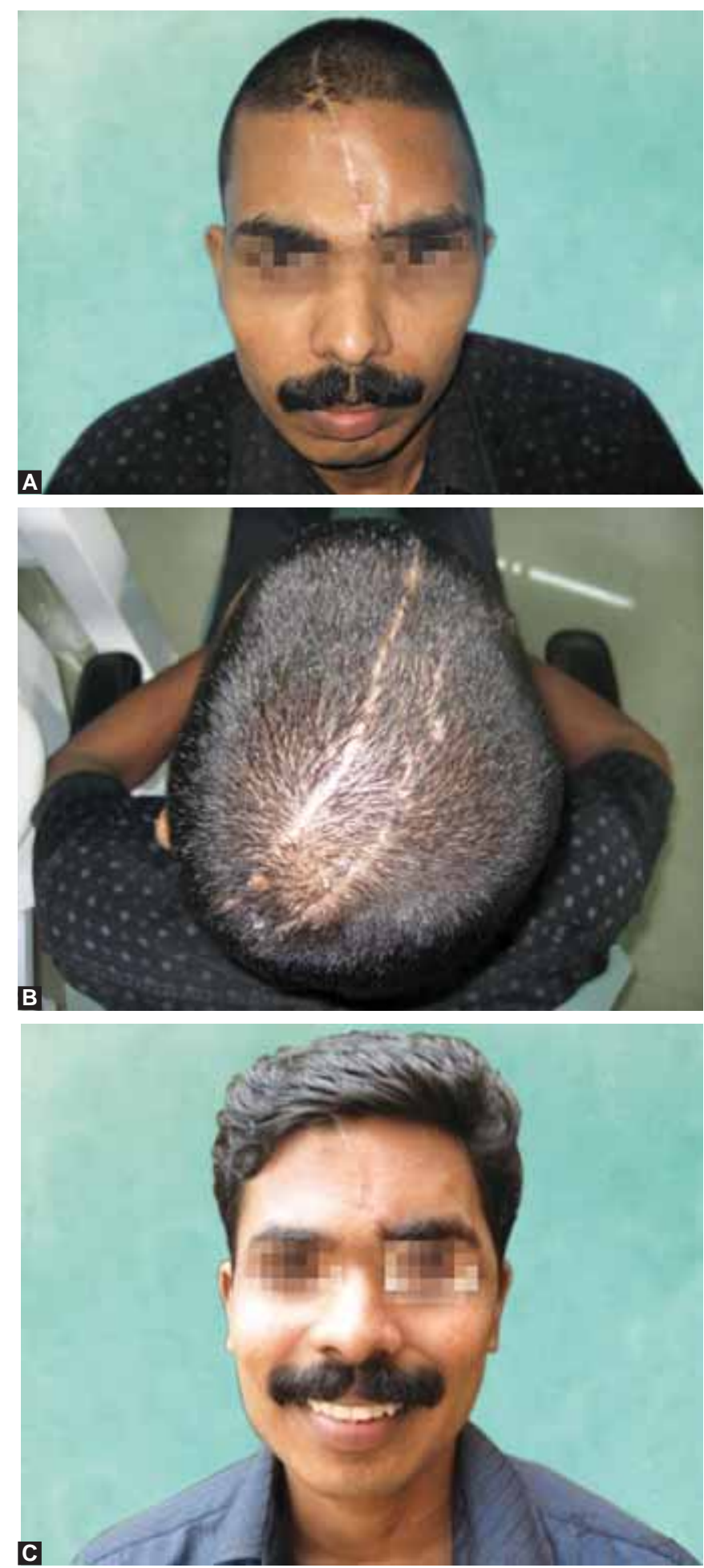

Figs 11A to C: Postoperative results after (A and $B) 10$ days (C) 4 months

Apart from cosmetic improvement, cranioplasty improves systemic cardiovascular and cerebral hemodynamic functions. ${ }^{10}$ Gardner reported a syndrome characterized by headaches, dizziness, irritability, epilepsy, discomfort and psychiatric syndromes that he had observed in patients with cranial defect. He called it the "syndrome of the trephined" and was the first to describe an improvement in the neurological function of some patients who underwent cranioplasty with tantalum. ${ }^{11-13}$ Unexpected improvements in the neurological status and in 
activities of daily living after cranioplasty in patients who had undergone previous craniectomy due to uncontrollable intracranial hypertension have been shown in several studies. ${ }^{13-14}$ The generally accepted explanation is that this neurological improvement might be due to a reduction of local cerebral compression effects by atmospheric pressure after cranioplasty, thereby increasing cerebral blood flow (CBF). ${ }^{15-18}$

The ideal attributes of cranioplasty materials include the following : Malleability, low cost, ease of use, ready availability, strength, inertness, radiolucency, nonferromagnetism, resistance to infection, capacity to grow, ease and stability of fixation to skull, compatibility with good cosmesis, nonrestorability, and nonthermoconductivity, sterilizability, nonionizability and noncorrosiveness. Currently, no cranioplasty material possesses all these characteristics. Nevertheless, one must choose among the various cranioplasty materials based on the best possible information about the attributes and availability of the materials, and the demands of the clinical situation. There are two basic methods for cranioplasty: (1) Osteoplastic reconstruction and (2) restoration with alloplastic implants.

The gold standard for skull reconstruction is autogenous cranial bone. In general, the use of autogenous bone is associated with low rates of infection and limited tissue reaction. In contrast, cranial bone is associated with additional donor site morbidity, has a limited volume of availability, can be difficult to shape and may be associated with long-term resorption. In general, its use is supported for the replacement of previously stored iatrogenic bone flaps, the reconstruction of small to mediumsized defects, and pediatric cranioplasty. ${ }^{6}$ In the case reported, the choice of osteoplastic reconstruction was neglected because of the large-sized defect and infected bone flap.

The next option available was restoration with Polymethylmethacrylate (PMMA). PMMA is a polymerized ester of arcylic acid. Methyl methacrylate was first used as a cranioplastic material by Zander in $1940 .{ }^{1}$ Autopolymerizing acrylic resin may be applied and adapted directly into a cranial defect, using saline irrigation to reduce heat from polymerization. However, presurgical fabrication of cranial prostheses is more desirable because reproduction of contour is more easily controlled and use of heat-processed resin is possible, resulting in a stronger prosthesis. PMMA cranioplasty should not be used in the presence of cranial infection, an open paranasal sinus, in the acute setting after a compound (open) head injury and in children less than 3 years of age. Compared to autologous bone, the main advantages of PMMA are ease of use and excellent cosmesis. Other advantages include ready availability, low cost, strength, stability, malleability, nonferromagnetism, nonionizability noncorrosiveness, and thermal nonconductivity. In terms of strength, PMMA is comparable to bone. Because of its brittleness, however, PMMA shatters into multiple fragments after fracture and, being radiolucent, the fractures of brittle acrylic plates cannot be detected and fragments cannot be located by radiographs. The major disadvantages of PMMA are a perceived increased susceptibility to postoperative infection and late complications. The susceptibility to risk of infection with PMMA is related to its nonviability and its fibrous encapsulation, which permits bacterial colonization. ${ }^{19}$ Considering high susceptibility of infection for PMMA, the alloplastic restoration with this material was also neglected in the case reported. Therefore, restoration of the skull defect by the next best available material, Titanium, was planned. Titanium (Ti22) was discovered in 1791 by William Gregor in England. Titanium was first used in cranioplasty in 1960's by Simpson. ${ }^{20}$ There are many physical properties of titanium to recommend its use as a cranioplasty material. Titanium is relatively radiolucent, nonferromagnetic and nonparamagnetic. Compared to other metals, titanium has a very low rate of corrosion, a low density and low modulous of elasticity. ${ }^{21}$ Another property of titanium is the accurate postoperative imaging without any major artifacts exploring the CT or MRI and the nonferromagnetic capacity permitting the safe examination in MRI high field, therefore being useful for long-term follow-up of the patients. Furthermore, titanium is associated with no toxicity, elicits no inflammatory reaction, and permits bone growth into its porous spaces (osseointegration) and through the openings of its mesh-like architecture. The literature indicates an infection rate of under $2 \%$ when using titanium $^{22-28}$ as compared to 10 to $12 \%$ when using acrylic. ${ }^{29}$ The high cost is its major disadvantage.

\section{Futuristic Approach}

Conventional technique has certain limitations that include difficulty in locating exact defect margins due to muscle and skin thickness and individual variations. Also, the dimensional changes of impression materials and dental stone and the patient discomfort are taken into consideration. The futuristic approach lies in the fabrication of three-dimensional cranial prosthesis by rapid prototyping and fused deposition modeling. ${ }^{30}$ The concept of osteoinduction has also been applied to cranioplasty with the evidences of BMPs. It can be anticipated that the implant of the future will give protection to the skull, be esthetically perfect and be osteoconductive and osteoinductive.

\section{CONCLUSION}

The number of patients requiring cranioplasty has increased considerably in recent years, due to the large number of cranial injuries occurring in this modern age. A case report of a patient has been illustrated who had a road traffic accident sustaining multiple fractures, including skull, followed by decompressive craniectomy and a cranioplasty rehabilitating his neurological status and cosmesis using a titanium cranial prosthesis with prosthodontists and neurosurgeons working as a team. Though the conventional method was used in the fabrication of the titanium cranial prosthesis, but satisfactory results were obtained both functionally as well as esthetically, which were the main goals of the treatment planning. 


\section{REFERENCES}

1. Beumer J III, Curtis TA, Marunick MT. Maxillofacial rehabilitation prosthodontic and surgical considerations. St Louis: Ishiyaku EuroAmerica 1996:455-77.

2. Beumer J III, Firtell DN, Curtis TA. Current concepts in cranioplasty. J Prosthet Dent 1979;42:67-77.

3. Martin JW, Ganz SD, King GE, Jacob RF, Kramer DC. Cranial implant modification. J Prosthet Dent 1984;52:414-16.

4. Richard D Jordan, James T White, Nathan Schupper. Technique for cranioplasty prosthesis fabrication. J Prosthet Dent August 1978;40(2).

5. James C. White Annals of Surgery, October 1948.

6. Jaskolka Michael S, Olavarria Greg. Reconstruction of skull defects. Atlas Oral Maxillofacial Surg Clin N Am 18, 2010: 139-49.

7. Abdulai AE, et al. Cranioplasty using polymethylmethacrylate implant constructed from an alginate impression and wax elimination technique. Ghana Medical Journal 2006 ;40(1):18-21.

8. Schmidek and sweet operative neurosurgical techniques, indications, methods and results, Vol. 2, 5th edition.

9. Rish BL, Dillon JD, Meirowsky AM, et al. Cranioplasty: A review of 1030 cases of penetrating head injury. Neurosurgery 1979;4:381-85.

10. Acta Neurochir Suppl 2008;102:15-20.

11. Dujovny M, Aviles A, Agner C, et al. Cranioplasty: Cosmetic or therapeutic. Surg Neurol 1997;47:238-41.

12. Grantham EG, Landis HP. Cranioplasty and the post-traumatic syndrome. J Neurosurg 1948;15:19-22.

13. Schiffer J, Gur R, Nisim U, et al. Symptomatic patients after craniectomy. Surg Neurol 1997;47:231-37.

14. Segal DH, Opperheim JS, Murovic JA. Neurological recovery after cranioplasty. Neurosurgery 1994;34:729-31.

15. Yamamura A, Sato M, Nakamura T, Uemura K, Makino H. Cranioplasty following decompressive craniectomy: Analysis of 300 cases. Neurol Surg 1977;5:345-53.

16. Langfitt TW. Increased intracranial pressure. Clin Neurosurg 1968;16:436-71.

17. Stula D. Cranioplasty: Indications, techniques and results. Springer, Vienna 1984.
18. Richaud J, Boetho S, Guell A, Lazorthes Y. Incidence des cranioplasties sur lafunction neurologique et le debit sangein cerebral. Neurochirurgia 1985;31:183-88.

19. Setti S Rengachary, Edward C. Calvarial and dural reconstruction, AANS Publication Committee. Benzel, USA: The American Association of Neurological Surgeons 1998:41-42.

20. Simpson D. Titanium in cranioplasty. J neurosurgery 1965; 22:292-93.

21. Elephterios Bogris, Dobrin N, Chiriac A. Titanium mesh cranioplasty for patients with large cranial defects: Technical notes. Romanian Neurosurgery 2010;XVII(4):456-60.

22. Blake GB, Macfarlane MR, Hinton JW. Titanium in reconstructive surgery of the skull and face. Br J Plast Surg 1990;43:528-35.

23. Chandler CL, Uttley D, Archer DJ, Macvicar D. Imaging after titanium cranioplasty. Br J Neurosurg 1994;8:409-14.

24. Eufinger H, Wehmioller M, Harders A, Heuser L. Prefabricated prostheses for the reconstruction of skull defects. Int J Oral Maxillofac Surg 1995;24:104-10.

25. Eufinger H, Wehmoller M, Machtens E, Heuser L, Harders A, Kruse D. Reconstruction of craniofacial bone defects with individual alloplastic implants based on CAD/CAM manipulated CT data. J Craniomaxillofac Surg 1995;23:175-81.

26. Heissler E, Fischer FS, Bolouri S, et al. Custom-made cast titanium implants produced with CAD/CAM for the reconstruction of cranium defects. Int J Oral Maxillofac Surg 1998;27:334-38.

27. Joffe JM, Mcdermott PJ, Linney AD, Mosse CA, Harris M. Computer generated titanium cranioplasty: Report of a new technique for repairing skull defects. Br J Neurosurg 1992;6: 343-50.

28. Joffe JM, Aghabeigi B, Davies EH, Harris M. A retrospective study of 66 titanium cranioplasties. Br J Oral Maxillofac Surg 1993;31:144-48.

29. Joffe JM, Nicoll SR, Richards R, Linney AD, Harris M. Validation of computer-assissted manufacture of titanium plates for cranioplasty. Int J Oral Maxillofac Surg 1999;28:309-13.

30. Gronet Peter M, Waskewicz Gregory A, Richardson Charles. Preformed acrylic cranial implants using fused deposition modeling: A clinical report. J Prosthet Dent 2003;90:429-33. 